1 and STT joints were assessed for synovitis (0-3) and bone marrow lesions (BMLs; 0-6 and 0-9, respectively). Radiographs were assessed for the presence of osteophytes in CMC-1 and STT joints following the OARSI atlas by two readers. Since pain was assessed for the TB as a whole, imaging scores of CMC-1 and STT joints were combined, comparing no change in both joints (i.e. 'stable') versus change in at least one joint. In TBs without maximum baseline pain, associations between increase in MRI features and increase in TB pain were investigated using logistic regression, presented as odds ratios (ORs) with 95\% confidence intervals (Cls). Similarly, in TBs with pain and MRI features present at baseline, associations between decrease in imaging features and decrease in TB pain were investigated.

Results: Out of 161 patients $(82.6 \%$ women, mean age 60.8 years, $91.3 \%$ fulfilling ACR hand OA criteria) 64 had TB pain at baseline (of whom 11 with maximal score). At the two-year follow-up visit, pain had decreased in 31 patients and increased in 33 patients. The majority had stable synovitis $(n=106)$ and BML $(n=96)$ scores over two years, although decreased ( $n=22, n=26$, resp.) and increased $(n=29, n=36$, resp.) scores were common. Increase in radiographic osteophytes was rarely $(n=10)$ observed. Increase in synovitis or BML was associated with increased pain, also after adjusting for baseline osteophyte status (Table). A decrease in BML was associated with a decrease in pain, although it did not reach statistical significance. Presence of osteophytes on baseline radiographs was weakly associated with change in pain in univariate analyses and attenuated when adjusting for the change in MRI features. Decrease of synovitis in patients with baseline pain was scarce $(n=7)$, therefore ORs were not computed.

Abstract THU0412 -Table 1.

Table 1 Longitudinal associations between change in MRI-defined synovitis or BMLs and change in thumb base pain in 161 patients with hand $\mathrm{OA}$ after two-year follow-up

\begin{tabular}{|c|c|c|c|}
\hline & $\begin{array}{l}\text { Change in pain } \\
\text { yes } / \mathrm{no}, \mathrm{n}\end{array}$ & $\begin{array}{l}\text { Crude } \\
\text { OR }(95 \% \mathrm{CI})\end{array}$ & $\begin{array}{l}\text { Adjusted* } \\
\text { OR }(95 \% \mathrm{CI})\end{array}$ \\
\hline \multicolumn{4}{|c|}{ Associations with increased pain } \\
\hline \multicolumn{4}{|c|}{$\begin{array}{l}\text { (in joints without maximum pain, } n=150 \text { ) } \\
\text { Delta synovitis }{ }^{-}\end{array}$} \\
\hline Stable/decrease & $20 / 99$ & 1 & 1 \\
\hline Increase & $12 / 15$ & $3.89(1.54-9.8)$ & $3.54(1.31-9.6)$ \\
\hline \multicolumn{4}{|c|}{ Delta bone marrow lesions $¥$} \\
\hline Stable/decrease & $16 / 98$ & 1 & 1 \\
\hline Increase & $15 / 18$ & $4.9(2.08-11.8)$ & $5.0(2.05-12.3)$ \\
\hline \multicolumn{4}{|l|}{ Baseline osteophytes§ } \\
\hline Absent & $13 / 69$ & 1 & 1 \\
\hline Present & $20 / 47$ & $2.02(0.90-4.5)$ & $1.68(0.70-4.0)$ \\
\hline \multicolumn{4}{|c|}{ Associations with decreased pain } \\
\hline \multicolumn{4}{|c|}{ (in joints with baseline pain, $n=64$ ) } \\
\hline \multicolumn{4}{|l|}{ Delta synovitist $\|$} \\
\hline Stable/Increase & $18 / 19$ & - & - \\
\hline Decrease & $4 / 3$ & - & - \\
\hline \multicolumn{4}{|c|}{ Delta bone marrow lesions $\neq \uparrow$} \\
\hline Stable/Increase & $10 / 17$ & 1 & 1 \\
\hline Decrease & $12 / 7$ & $2.91(0.86-9.8)$ & $3.10(0.90-10.7)$ \\
\hline \multicolumn{4}{|l|}{ Baseline osteophytes } \\
\hline Absent & $10 / 9$ & 1 & 1 \\
\hline Present & $21 / 24$ & $0.79(0.27-2.31)$ & $0.84(0.28-2.52)$ \\
\hline
\end{tabular}

Conclusion: In this cohort of hand OA patients, thumb base pain levels varied over the course of two years in approximately forty percent of patients. Changes in MRI-defined synovitis and BMLs of the TB joints were positively associated with change in pain on palpation. Baseline osteophytes were not significantly associated with change in pain. While cross-sectionally MRI-defined inflammation may be a less important determinant of pain than radiographic damage, this study shows that a change in inflammatory features may indeed be relevant.

Disclosure of Interests: : Sjoerd van Beest: None declared, H.M. Kroon: None declared, Monique Reijnierse Grant/research support from: Funding from the Dutch Arthritis Foundation. The funding source had no role in the design and conduct of the study., Frits Rosendaal: None declared, Margreet Kloppenburg Grant/research support from: Pfizer, IMI-APPROACH (Grant Agreement $n^{\circ}$ 115770), Consultant for: GlaxoSmithKline, MerckSerono, Abbvie, Levicept, Pfizer, Féline P.B. Kroon: None declared DOI: 10.1136/annrheumdis-2019-eular.1593

\section{THU0413 \\ MAJOR SUB-HAPLOGROUP H1 IS A RISK FACTOR FOR RAPIDLY PROGRESSIVE OSTEOARTHRITIS OF THE} KNEE. DATA FROM THE OSTEOARTHRITIS INITIATIVE

Alejandro Durán-Sotuela, Mercedes Fernandez-Moreno, Maria Eugenia Vazquez Mosquera, Paula Ramos-Louro, Andrea Dalmao-Fernandez, Sara Relaño-

Fernandez, Natividad Oreiro, Francisco J. Blanco, Ignacio Rego-Perez. Instituto de Investigación Biomédica de A Coruña (INIBIC), Servicio de Reumatología, A

Coruña, Spain

Background: There is a pressing need to identify individuals with accelerated osteoarthritis to include them in clinical trials and to implement prevention strategies. During the last years, the mtDNA haplogroups have been consistently associated with $\mathrm{OA}$ in terms of genetic factors influencing both the incidence and progression of the disease $(1,2)$

Objectives: To analyze the influence of mtDNA haplogroups on the risk of rapid knee OA progression in patients from the Osteoarthritis Initiative (OAl)

Methods: We selected Caucasian patients from the OAl that were assigned into three different groups based on previously described criteria: i) rapid progressors, with baseline $\mathrm{KL}$ grade $0-\mathrm{I}$ in at least one knee and increase up to $\mathrm{KL} \geq \mathrm{III}$ during 48 month follow-up; ii) non-rapid progressors, with baseline KL grade $0-1$ in at least one knee and increase up to $\mathrm{KL}=\|$ during 48 month follow-up; and iii) non-progressors, with $\mathrm{KL}$ grade $0-I$ at baseline in at least one knee and bilaterally stable during the 48-month follow-up period. We performed different regression models adjusting for the confounder clinical variables of gender, age, body mass index, contralateral OA, previous injury in target knee and total WOMAC mtDNA haplogroups and major $\mathrm{H}$ sub-haplogroups $\left(\mathrm{H} 1, \mathrm{H} 3, \mathrm{H} 5\right.$ and $\left.\mathrm{H}^{*}\right)$ were previously assigned using sequencing techniques. The analyses were performed using IBM SPSS Statistics v24

Results: We could assign the progression status to 2092 subjects, of which 181 were rapid progressors $(8,7 \%), 321$ non-rapid progressors $(15,3 \%)$ and 1590 non-progressors $(76 \%)$.

All the classical risk factors for disease progression showed significant differences between rapid progressors and non-progressors, including gender (female) (OR=1,934; 95\%Cl:1,377-2,717; $\mathrm{p}<0,001$ ), age (OR=1,040;95\% $\mathrm{Cl}: 1,021-1,060 ; \mathrm{p}<0,001)$, BMI $(\mathrm{OR}=1,113 ; 95 \% \mathrm{Cl}: 1,073-1,154 ; \mathrm{p}<0,001)$, contralateral OA $(\mathrm{OR}=2,710 ; 95 \% \mathrm{Cl}: 1,938-3,773 ; \mathrm{p}<0,001)$, previous injury of target knee $(\mathrm{OR}=2,849 ; 95 \% \mathrm{Cl}: 2,032-4,000 ; \mathrm{p}<0,001)$ and total WOMAC (OR=1,016;95\%Cl:1,008-1,023;p<0,001). In terms of haplogroups, compared with the most common haplogroup $\mathrm{H}$, the haplogroup $\mathrm{J}$ showed a lower frequency in the rapid progressors group in relation to non-progressors, although this difference did not reach the statistical significance $(\mathrm{OR}=0,526 ; 95 \% \mathrm{Cl}: 0,251-1,101 ; \mathrm{p}=0,088)$. When the analysis included the major $\mathrm{H}$ subtypes, the most frequent sub-haplogroup $\mathrm{H} 1$ appeared overrepresented in the rapid progressors group in relation to both non-progressors $(\mathrm{OR}=1,832 ; 95 \% \mathrm{Cl}: 1,102-3,044)$ and non-rapid progressors $(\mathrm{OR}=1,587 ; 95 \% \mathrm{Cl}: 0,876-2,877)$, being this difference statistically significant in the case of non-progressors $(p=0,020)$.

After re-categorizing the dependent variable into rapid-progressors and non-rapid progressors, in addition to the significant association of the classical risk factors such as gender (female), age, BMI, contralateral OA, previous injury of target knee and total WOMAC at baseline, the subhaplogroup $\mathrm{H} 1$ appeared significantly associated as a risk factor for rapid progression too (OR=1,781;95\%Cl:1,08 $-2,919 ; \mathrm{p}=0,022)$

Conclusion: The mtDNA haplogroups, more specifically the major subhaplogroup $\mathrm{H} 1$, increase the risk of rapidly progressive $\mathrm{OA}$ of the knee. The assignment of this mitochondrial genetic sub-haplogroup could be useful as complementary genetic biomarker for the early identification of this OA phenotype

\section{REFERENCES}

[1] Fernández-Moreno, et al. Ann Rheum Dis 2017;76(6):1114-1122

[2] Fernández-Moreno, et al. Rheumatology (Oxford) 2017;56(2):263-270

Disclosure of Interests: Alejandro Durán-Sotuela: None declared, Mercedes Fernandez-Moreno: None declared, Maria Eugenia Vazquez Mosquera: None declared, Paula Ramos-Louro: None declared, Andrea Dalmao-Fernandez: None declared, Sara Relaño-Fernandez: None declared, Natividad Oreiro: None declared, Francisco J. Blanco Consultant for: AbbVie, Bioiberica, BMS, GSK, Grünenthal, Janssen, Lilly, Pfizer, Regeneron, Roche, Sanofi, TRB Chemedica, and UCB, Ignacio RegoPerez: None declared

DOI: 10.1136/annrheumdis-2019-eular.4087 